\title{
Effect of Non-Steroidal Anti-Inflammatory Drugs on Sport Performance Indices in Healthy People: a Meta-Analysis of Randomized Controlled Trials
}

Catherine Cornu $u^{1,2,3,4^{*}}$ D, Clémence Grange ${ }^{5+}$, Amanda Regalin ${ }^{5+}$, Justine Munier ${ }^{5+}$, Sonia Ounissi ${ }^{5 \dagger}$, Natane Reynaud ${ }^{5}$, Behrouz Kassai-Koupai ${ }^{1,2,3}$, Pierre Sallet ${ }^{6}$ and Patrice Nony ${ }^{2,3+}$

\begin{abstract}
Background: Non-steroidal anti-inflammatory drugs (NSAIDs) are medications that are frequently used by athletes. There may also be some abuse of these substances, although it is unclear whether NSAIDs in fact enhance performance.

We performed a systematic review and meta-analysis to evaluate the effect of NSAIDs on sport performance indices.

Methods: We selected randomized trials from the PubMed and Cochrane Library databases investigating the effects of NSAIDs on sport performance. Volunteers could be healthy adult men and women. Any NSAID, administered by any route, taken prior to any type of exercise, and for any duration could be used. The control intervention could be a placebo, an active substance, or no intervention. We included doubleblind, single-blind, and open-label studies. The primary outcome was the maximum performance in exercises as defined in each study. The secondary outcomes were the time until self-reported exhaustion and the self-reported pain.

Results: Among 1631 records, we retained thirteen parallel-group and ten crossover studies, totaling 366 and 148 subjects, respectively. They were disparate regarding treatments, dose and duration, and the type of exercise. There was neither significant difference in the maximum performance between NSAIDs and control groups nor in the time until exhaustion nor in self-perceived pain.

Conclusions: The existence of an ergogenic effect of NSAIDs on sport performance indices was unable to be concluded, since the level of evidence of the studies is low, the doses tested, and the exercises performed are very heterogeneous and far from those observed in real-life practices. More studies are required.
\end{abstract}

Keywords: Anti-inflammatory agents, Non-steroidal, Athletic performance, Healthy volunteers, Doping in sport

\footnotetext{
* Correspondence: catherine.cornu@chu-lyon.fr

${ }^{\dagger}$ Clémence Grange, Amanda Regalin, Justine Munier, Sonia Ounissi and

Patrice Nony contributed equally to this work.

'INSERM, CIC1407, 69500 Bron, France

²UMR 5558, Université Claude Bernard Lyon 1, 69100 Lyon, France

Full list of author information is available at the end of the article
}

\section{Springer Open}

(c) The Author(s). 2020 Open Access This article is licensed under a Creative Commons Attribution 4.0 International License, which permits use, sharing, adaptation, distribution and reproduction in any medium or format, as long as you give appropriate credit to the original author(s) and the source, provide a link to the Creative Commons licence, and indicate if changes were made. The images or other third party material in this article are included in the article's Creative Commons licence, unless indicated otherwise in a credit line to the material. If material is not included in the article's Creative Commons licence and your intended use is not permitted by statutory regulation or exceeds the permitted use, you will need to obtain permission directly from the copyright holder. To view a copy of this licence, visit http://creativecommons.org/licenses/by/4.0/. 


\section{Key Points}

- Meta-analysis of the effects of non-steroidal antiinflammatory drugs (NSAIDs) on sports performance indices in healthy individuals showed that the level of evidence in available studies is low, the doses of NSAIDs used are heterogeneous and very different from those administered in ordinary usage, and that the type of exercises performed is very disparate.

- As a consequence, the meta-analysis did not allow conclusions to be drawn about the existence of an ergogenic effect of NSAIDs on sport performance indices.

\section{Background}

Non-steroidal anti-inflammatory drugs (NSAIDs) are a heterogeneous class of drugs chemically unrelated and known to have potent anti-inflammatory, analgesic, antipyretic, and antithrombotic effects. NSAIDs are also associated with an increased risk of adverse gastrointestinal, renal, and cardiovascular effects [1]. In sports medicine, NSAIDs are delivered as oral, topical, intramuscular, or, less commonly, intravenous preparations for treating softtissue disorders, joint injury, osteoarthritis, inflammatory arthropathies, fractures, hematoma, and also postoperatively $[2,3]$.

Athletes use NSAIDs more than any other medication. For example, during the 2000 Olympic Games in Sydney, one in four athletes reported using NSAIDs 3 days before drug testing $[4,5]$. During the 2002, 2006, 2010, and 2014 Fédération Internationale de Football Association (FIFA) World Cups, the mean intake was of 0.77 drugs per player and per match; NSAIDs were the most frequently prescribed drugs (36\% of drugs), and a similar level of intake was found during the 2003 and 2007 Women's World Cups [6]. Athletes take NSAIDs for preventing pain, continuing athletic activities in spite of injuries, or accelerate return to function after injury $[3,7,8]$. If taken immediately before or following injury, NSAIDs can reduce musculoskeletal pain and accelerate the return of function [8]; the randomized controlled trial published by Ekman et al. showed that NSAIDs enabled more patients to resume normal walking on days 4 and 7 than placebo or tramadol $[8,9]$. However, NSAIDs have side-effects including asthma exacerbation; gastrointestinal and renal side-effects including acute kidney injury; hypertension; and other cardiovascular diseases $[3,10-14]$. Therefore, NSAID use presents a potential health risk for athletes.

The World Anti-Doping Agency (WADA) Prohibited List includes any substance and methods that satisfy two of the following criteria: a drug that "has the potential or enhances sport performance," represents an actual or potential health risk for athletes or violates the spirit of sport described in the WADA Code [15]. NSAIDs are not on the WADA list although they represent an actual or potential health risk for athletes because they are not considered as performance-enhancing drugs [16].

Little is known about NSAID effects on exerciserelated physiology and performance. No ergogenic effect might be expected from two studies using them $[17,18]$. The action of NSAIDs on pain might enable performing exercise or continuing exercising instead of taking time off training for healing [4]. However, because NSAIDs exert a pharmacologic action on key physiological systems related to exercise performance, a theoretical rationale exists whereby these drugs could provide a significant ergogenic effect [19].

In order to identify whether NSAIDs "have the potential or enhance sport performance," we conducted a systematic review and meta-analysis of randomized controlled trials, the reference method to update medical evidence for developing clinical practice guidelines and for designing clinical research [20,21].

\section{Methods}

\section{Inclusion and Exclusion Criteria}

We selected randomized controlled clinical trials investigating the effects of NSAIDs on performance indices in sport. The inclusion criteria included male and female healthy participants including but not limited to athletes, aged over 18 years. The number of participants was not a selection criterion. Any type of NSAIDs, including aspirin, could be used, administered by any route, and at any dose. NSAIDs had to be taken prior to any type of physical exercise, and exposure could be of any duration. The control intervention could be either a placebo, an active substance, or no intervention. We included double-blind, single-blind, and open-label studies. Exclusion criteria were performance criterion unavailable and non-human studies.

The primary outcome was the maximal exercise performance reached, as defined in each study. Secondary outcomes were the time until self-reported exhaustion and self-reported pain. The measure of physical performance could be either a physiological measure (e.g., $\mathrm{VO}_{2} \max$ ) or a measure of strength, acceleration, etc.

\section{Search Strategy}

Two authors (CG, PN) searched the PubMed (which comprises citations for biomedical literature from MEDLINE, life science journals, and online books) and the Cochrane Library databases up to December 2019 with a combination of Medical Subject Headings (MeSH) or equivalent, or text word terms; search strategies were tailored to individual databases. The full search strategy for the PubMed database is shown in supplementary 
material, Appendix 1. No restrictions on language or year of publication were applied. ClinicalTrials.gov and Researchgate.net were searched for unpublished and ongoing trials. Reference lists in included (and excluded) studies and reviews were also searched for additional studies. The selection of relevant articles was performed by two authors independently (AR, SO, PN, CC) based on the abstract and title. For articles that could not be excluded with certainty on the basis of the title and the abstract, the full text was analyzed.

\section{Data Extraction}

All relevant data were extracted by two authors independently (AR, SO, PN) and included the first author, year of publication, study design, sample size, population characteristics, type of intervention, measured outcomes, and respective numerical values.

When the numerical values of outcomes for studies were not available or needed clarification $(n=4)$, the authors were contacted by email. No response was received in two cases. For these studies, the corresponding values were extracted from graphs using Engauge Digitizer 3.0.

When measurements were performed at different time points, we used the closest to the known peak plasma concentration of each molecule. Given the expected diversity of measured outcomes across studies, the slowest speed for isokinetic exercises was considered; eccentric movements when available, otherwise concentric or isotonic movements, and for sprint tests, the highest speed was used.

\section{Quality Assessment}

Three authors (CG, SO, CC) independently assessed the risk of bias for each study according to the criteria presented in the Cochrane Handbook for Systematic Reviews of Interventions version 5.1.0 [22]. Each study was analyzed for random sequence generation, allocation concealment, blinding of participants and personnel, blinding of outcome assessment, incomplete outcome data, selective reporting, and other bias; the risk of bias arising from each domain is judged as "low," "high," or "unclear." In case of disagreement, a consensus was sought through a discussion between six authors (CG, SO, JM, AR, CC, PN). Publication bias was assessed using a funnel plot [22].

\section{Statistical Analysis}

The meta-analysis was performed using Review Manager (RevMan) Version 5.3., The Cochrane Collaboration, 2014. The results are expressed as standardized mean differences (SMD) with a corresponding 95\% confidence interval $(\mathrm{CI})$. A $p$ value $<0.05$ was considered statistically significant.
In a crossover design, participants are randomized initially to an intervention or control, and then "crossover" to control or intervention, respectively. There are two options to include crossover trials in a meta-analysis: when only data from the first period is available, crossover trials are handled like parallel-group trials. When data for all periods are available, crossover trials should be analyzed separately. Crossover trials that could not be included in the parallel-group meta-analysis were analyzed separately, as recommended by the Cochrane Collaboration [22]. The SMD and the corresponding standard error (SE (SMD)) were computed using the formula recommended by the Cochrane Handbook for Systematic Reviews of Interventions version 5.1.0 part 3 chapter 16.4.6.2. A correlation coefficient for the calculation of the SE (SMD) of 0.5 was chosen arbitrarily; we performed simulations/sensitivity analysis with three other values: $0,0.25$, and 0.75 .

The $I^{2}$ test was used to quantify the heterogeneity between studies; we considered that heterogeneity might not be important if $I^{2}<50 \%$ : in such a situation, a fixedeffects model was used. When $I^{2}$ was $\geq 50 \%$ for a given outcome, a random-effects model was used.

The heterogeneity was addressed by identifying study(ies) likely to bring heterogeneity; identifying the characteristics of this(ese) study(ies), which may create heterogeneity; identifying study(ies) having the same characteristics, and performing analyses with and without the studies potentially leading to heterogeneity. If the heterogeneity disappeared, we could possibly relate the heterogeneity to this(ese) characteristic(s). A subgroup analysis was performed for parallel-arm studies assessing ibuprofen, the most commonly used NSAID in the included studies.

\section{Results}

From a total of 1631 records identified, 23 studies were included in the meta-analysis. A total of 1594 records were excluded based on their title and abstract as they did not evaluate sport performance indices, did not assess the topics of interest, or were animal studies. Fortynine articles were fully reviewed; from the bibliography of these six, additional articles were selected and reviewed. Twenty articles were excluded because they did not assess the outcomes of interest, and data could not be extracted from the reported graphs, inadequate intervention; a total of 23 studies were included [17, 18, 23-42] (Fig. 1).

The characteristics of the included studies are shown in Table 1. One crossover study could be included in the parallel-group analysis [28]; twelve studies compared ibuprofen to placebo [25-30, 32, 36, 39, 41-43], one study compared ibuprofen to low-dose $(75 \mathrm{mg}$ ) aspirin [34], one study compared indomethacin to placebo [35] 


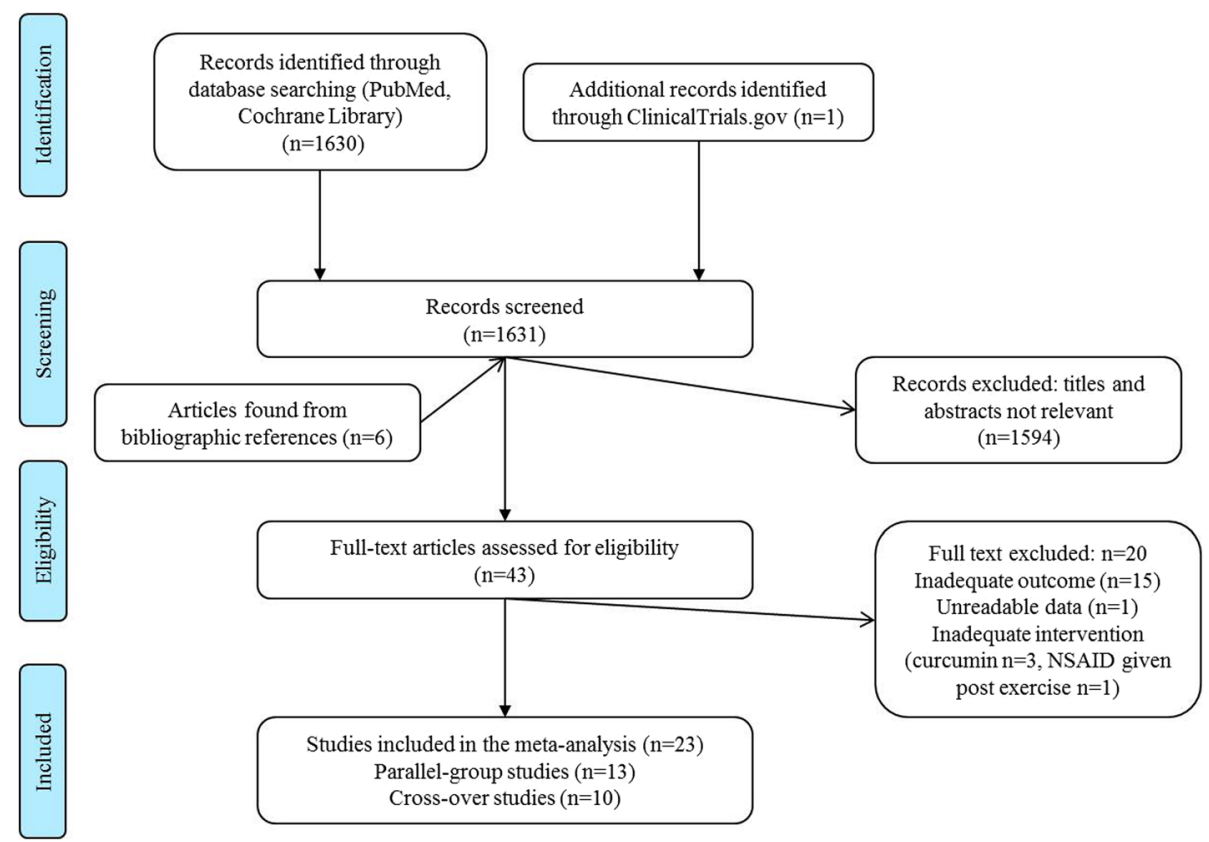

Fig. 1 Flow diagram of study selection for the meta-analyses

or no treatment [24], three studies compared aspirin to placebo $[17,18,38]$, and one study compared flurbiprofen to placebo [40]. One study was conducted in postmenopausal women [29]; other studies included young healthy participants. One study was conducted in an open long-distance setting [27]; all other studies were conducted in a sports science center setting. All studies were randomized controlled trials.

A total of 296 participants were included in the parallel-group primary outcome meta-analysis (12 parallel-group studies and 1 first period of crossover studies) and 135 participants in the crossover metaanalysis (10 crossover studies). One study included postmenopausal women [29], one included older men and women [43], six included both males and females [23, 30, 32, 34, 41, 43], and all other studies included male subjects. Seven parallel-group studies included athletic, well-trained, or young people who regularly practiced sport [17, 18, 24-27, 40, 42]; the other studies included untrained, non-active, or non-athletic subjects. All participants were healthy.

One study investigated a transdermal route for NSAID administration [40]. Seven parallel-group studies and three crossover studies investigated an acute administration whereas other studies investigated a longer period of treatment that ranged from $10 \mathrm{~h}$ to 1 week before exercise. The dose of ibuprofen investigated ranged from $400 \mathrm{mg}$ to $1.2 \mathrm{~g}$ per intake, aspirin from $500 \mathrm{mg}$ to $1000 \mathrm{mg}$ per intake, and indomethacin from $75 \mathrm{mg}$ to $150 \mathrm{mg}$ per day.

Interventions and outcome measurements varied across trials and are shown in Table 1 . Sixteen studies used force exercises: five used isometric force, nine used eccentric force, and two isotonic/isokinetic force; thirteen had force outcome measures: ten used maximal contraction, two used peak torque, and one used peak power. Four studies used running exercises: longdistance running (one study), one used jump performance after running, short distance (one study, with time for running $3.2 \mathrm{~km}$ as outcome), and one sprint running (with acceleration as outcome). Three used treadmill running with $\mathrm{VO}_{2}$ max as outcome. Three studies used bicycle exercise and measured the maximum workload.

\section{Quality Assessment}

Quality assessment of the included studies is shown in Fig. 2. One parallel-group study was open-label [39], and three were single-blind studies $[18,34,40]$, with a substantial risk of bias. Incomplete outcome data (attrition bias) was present in five studies. Selective reporting bias could be excluded for only three of the included studies since the study protocols were registered. Therefore, in most studies, some planned outcomes may not have been reported and, conversely, unplanned outcomes may have been reported.

\section{Outcome Measures \\ Primary Outcome: Maximum Performance}

Parallel-Group Meta-Analysis Thirteen studies reported the maximum performance, totaling 149 participants in the NSAID group and 147 participants in the control group. There was no significant difference in the 


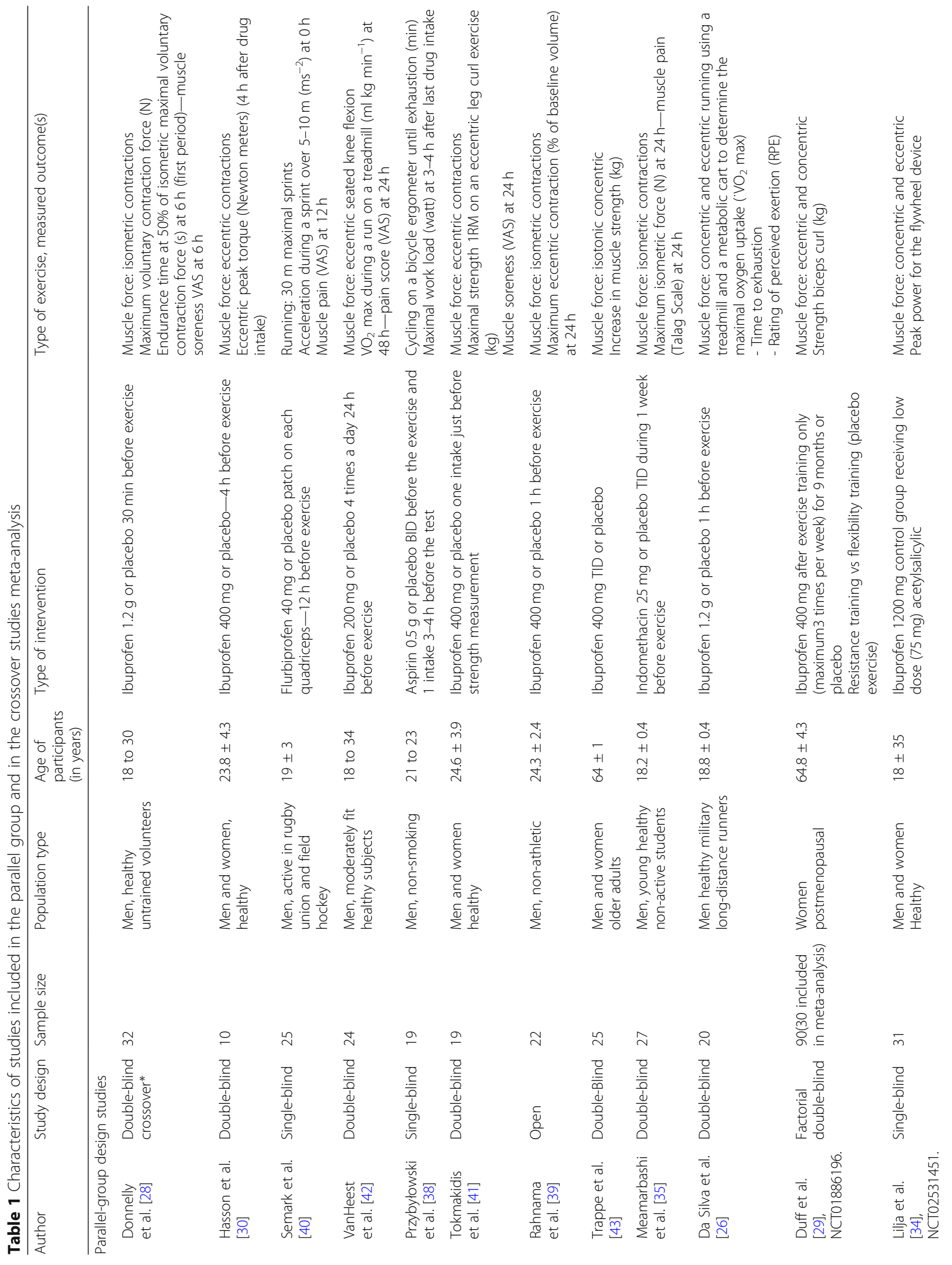




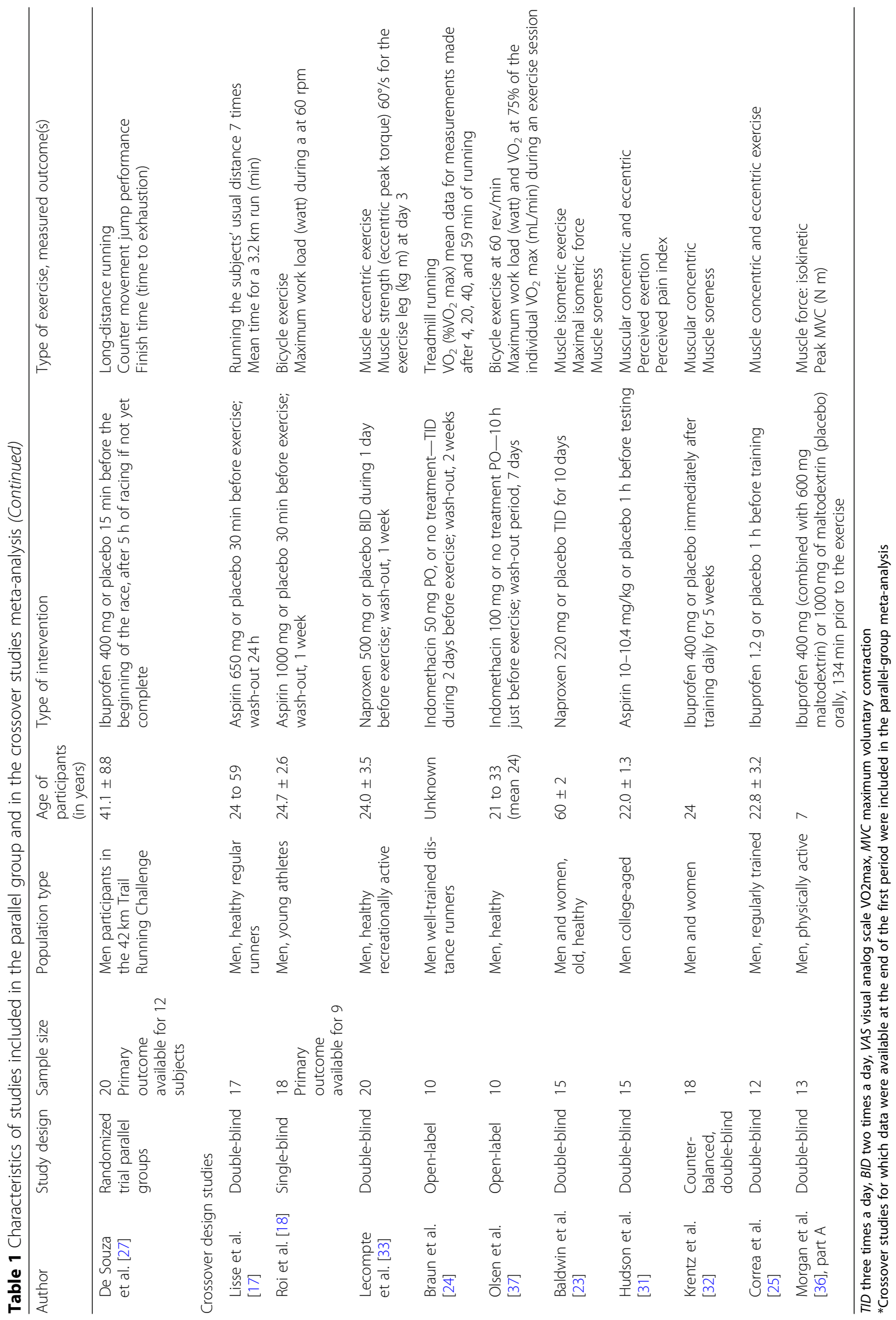




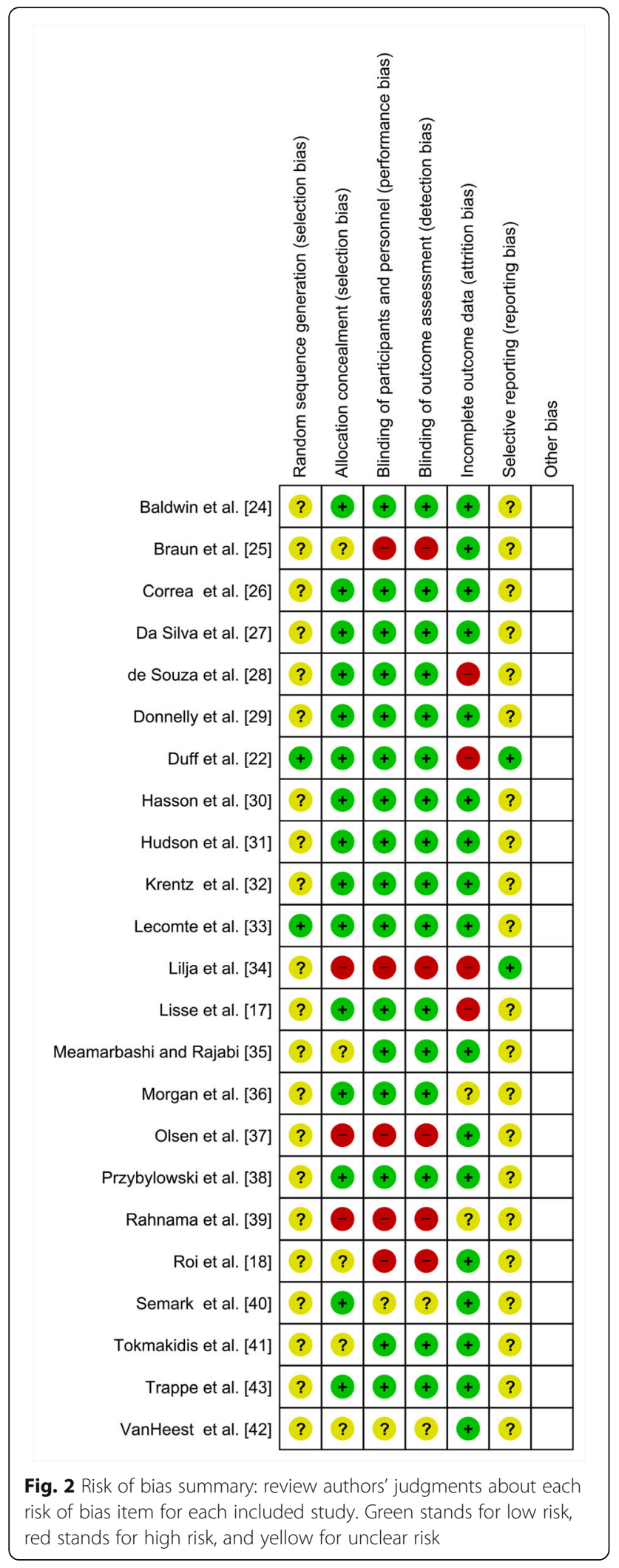

maximum performance between groups (SMD, - 0.03; $95 \%$ CI $[-0.26,0.20])$ using a fixed-effects model $\left(I^{2}=\right.$ 22\%; Fig. 3a).

Crossover Meta-Analysis Nine studies reported a maximum performance index, totaling 135 participants. There was no significant difference in the maximum performance indices between groups (SMD, 0.01; 95\% CI $-0.39,0.40)$ using a fixed-effect model $\left(I^{2}=0 \%\right)$ and a correlation coefficient of 0.5 (Fig. 3b). Analyses with different values of the correlation coefficient showed similar results, all being non-significant.

\section{Secondary Outcomes: Time Until Exhaustion}

Parallel-Group Meta-Analysis Four studies reported the outcome "time until exhaustion," totaling 44 participants in the NSAID group and 39 participants in the control group. There was no significant difference in the time until exhaustion between groups (SMD, $-0.11 ; 95 \%$ CI -0.55 , $0.33)$ using a fixed-effect model $\left(I^{2}=0 \%\right.$; Fig. 4). Time until exhaustion was not available for crossover studies.

\section{Secondary Outcomes: Self-Perceived Pain}

The assessment of the self-perceived pain was available for six studies, totaling 72 participants in the NSAID group and 75 participants in the control group. Selfperceived pain was not significantly lower in the NSAID group than in the control group (SMD, - 0.32; 95\% CI $0.65,0.01)$ using a fixed-effect model $\left(I^{2}=36 \%\right.$; Fig. 5). Self-perceived pain was not available for crossover studies.

\section{Sub-Group Analyses: Ibuprofen Versus Control Group}

Parallel-Group Meta-Analysis The maximum performance reached by the participants in the trials assessing ibuprofen versus placebo was available for ten studies totaling 112 participants in the ibuprofen group and 113 participants in the control group. There was no significant difference in the maximum performance between groups (SMD, 0.02; 95\% CI - 0.24, 0.29) using a fixedeffect model $\left(I^{2}=0 \%\right.$; Supplementary Figure 1$)$.

\section{Heterogeneity}

There was no heterogeneity in any analysis.

\section{Adverse Effects}

No adverse effects were reported in the studies included. History of gastrointestinal disorders was an exclusion criterion in all studies. 


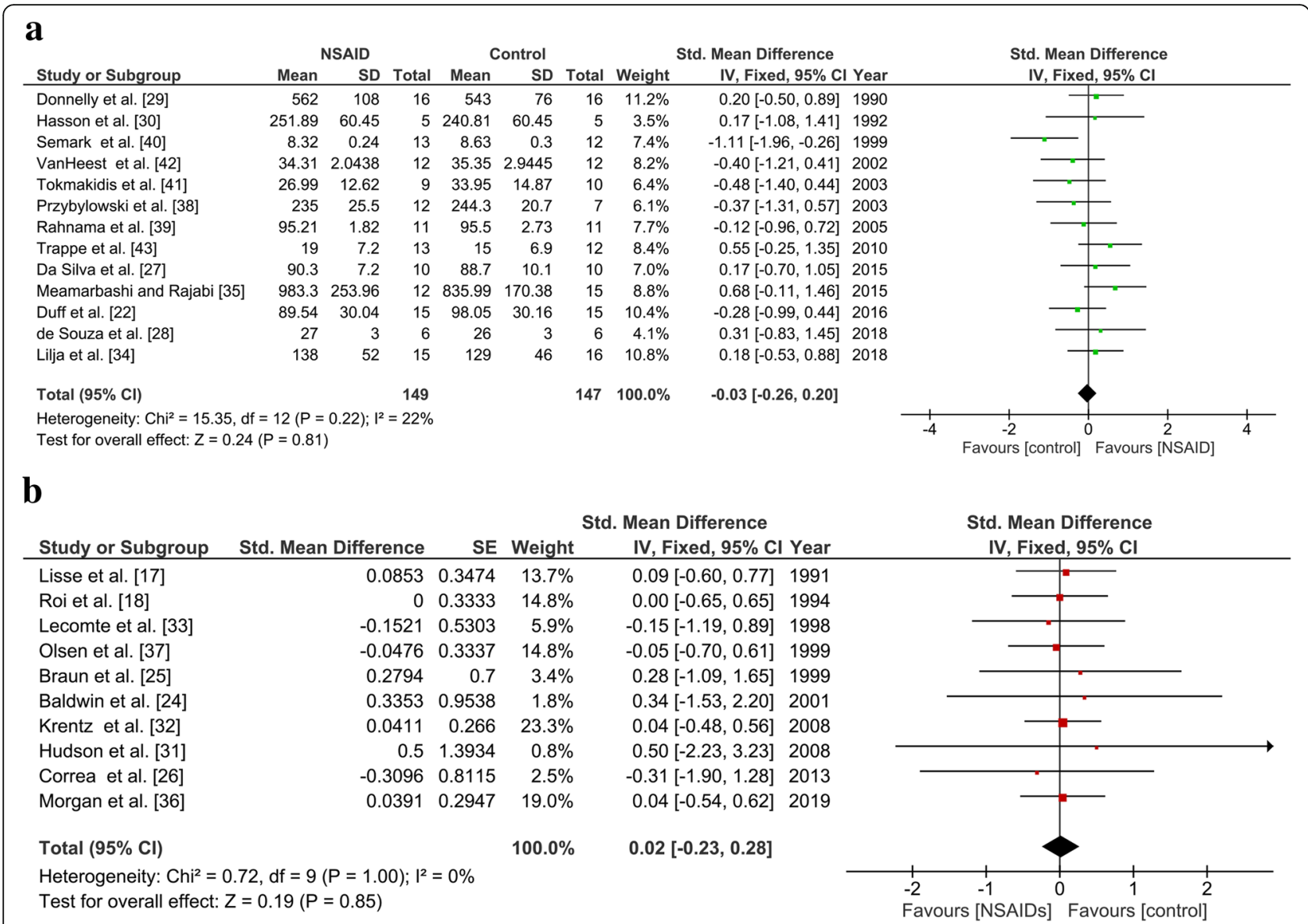

Fig. 3 Forest plot of the primary outcome, maximum performance $\mathbf{a}$ in the parallel-group studies and $\mathbf{b}$ in the crossover studies (correlation coefficient $=0.5$ )

\section{Correlation Coefficient of the Crossover Trials Analysis}

The sensitivity analysis performed using $0,0.25$, and 0.75 values for the correlation coefficient found the same results as the analysis using the correlation coefficient of 0.5 (results not shown).

\section{Publication Bias}

The number of included studies was insufficient to allow a robust interpretation of funnel plots. However, the funnel plot for the primary outcome (Supplementary Figure 2) was well distributed.

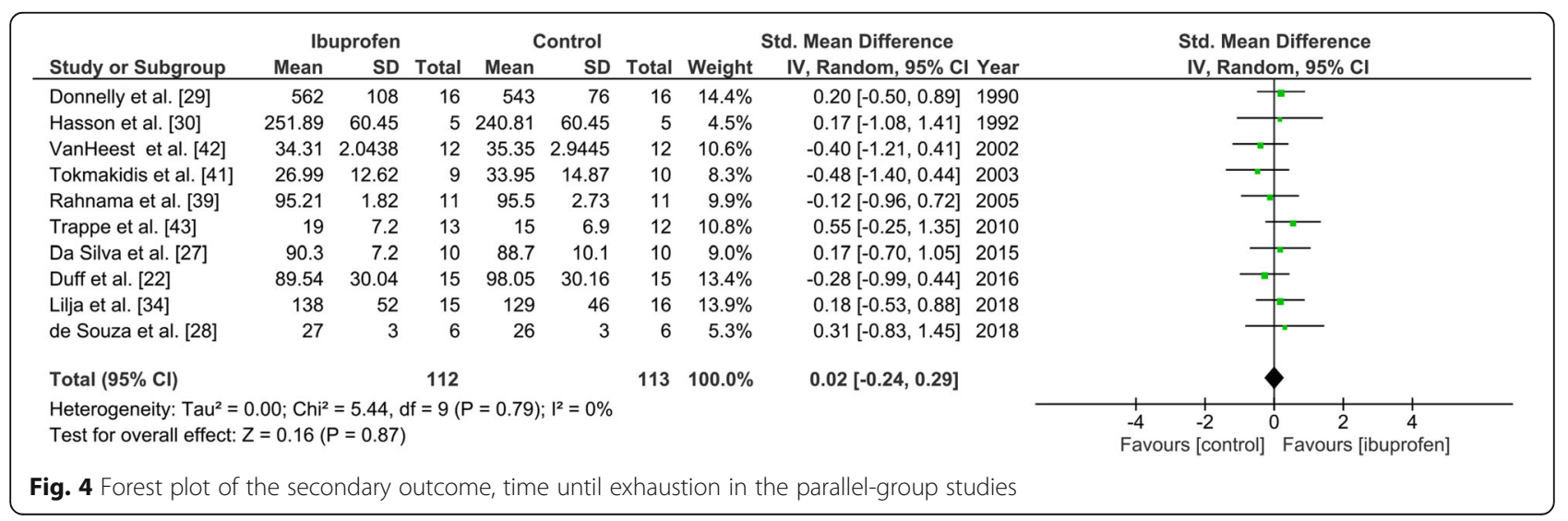




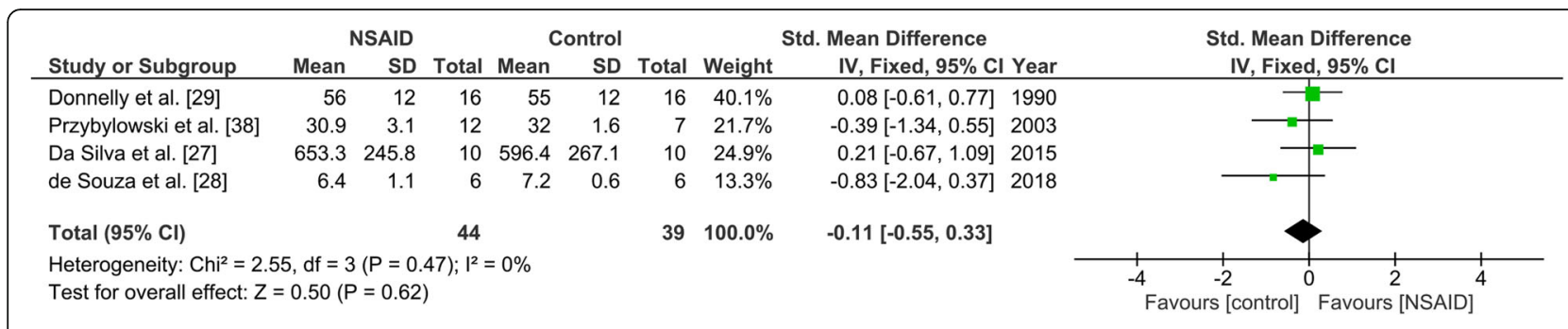

Fig. 5 Forest plot of the secondary outcome, self-perceived pain in the parallel-group studies

\section{Discussion}

Because NSAIDs exert a pharmacologic action on key physiological systems related to exercise performance, a theoretical rationale exists whereby these drugs could provide a significant ergogenic effect [19]. They are widely used for concealing pain and therefore allowing continuing a sports activity.

This meta-analysis did not show that NSAIDs significantly impacted sport performance indices in healthy people. NSAIDs did not reduce time to exhaustion, or self-perceived pain, although there was a trend toward a reduction of pain.

Studies included in this meta-analysis are very disparate. For instance, some studies included athletic, welltrained, or young people who regularly practiced sport; others included untrained, non-active, or non-athletic subjects; and one included post-menopausal women. The treatments investigated differed in terms of drug, dose, and duration of treatment, and finally, the type of exercise also differed between studies. The reported outcomes were different, and this is why we used the standardized mean difference [44] for the measurement of association in the meta-analysis. The assumption behind this use is that the differences in standard deviations among studies reflect differences in measurement scales and not real differences in variability among study populations. This assumption may be problematic when real differences in variability between the participants in different studies are expected. Here we can assume that despite differences between studies, the similarities of their setting, the inclusion of healthy participants, and the use of drugs of a unique class means the use of SMD is not flawed.

All but one study were performed in an experimental setting, such as a sports science center setting, and their designs do not mimic real practices of athletes. In most studies, the drug was administered before exercise, immediately before or up to $12 \mathrm{~h}$ before; in two studies, it was administered three times or four times a day from $24 \mathrm{~h}$ to 1 week before exercise. The doses used were much lower than the dangerous overuse taken by athletes during competitions, i.e., parenteral administration, concomitant use of several different
NSAIDs on the same day, inappropriate dosing (too low or too high dosing, e.g., up to 8 tablets of diclofenac in one day), and drug interactions ( with asthma treatment, with antibiotics); use of outmoded drugs such as phenylbutazone, (used 11 times, 6 by injection), a potent NSAID with a long half-life, has a wide range of adverse effects, particularly relating to the stomach and bone marrow, in even small doses, as underlined by Corrigan and al [4]. The exercise was a single bout exercise and was not as prolonged as in competitions. Therefore, these results could not be extrapolated to sport competition conditions.

Considering NSAID side effects, the study reported by Lipman et al. was aimed at evaluating ibuprofen versus placebo effect on acute kidney injury in ultra-marathons [45]. The conclusion of the authors was that ibuprofen non-significantly increased the incidence of acute kidney injury by $18 \%$ ( $95 \%$ CI $-4 \%$ to $41 \%$ ). This study, which was performed in a real setting of an ultra-marathon, did not report performance outcome and could not be included in this meta-analysis. However, Lilja et al. conclude that "maximal over-the-counter doses of ibuprofen attenuate strength and muscle hypertrophic adaptations to 8 weeks of resistance training in young adults" [34]. Thus, young individuals using resistance training to maximize muscle growth or strength should avoid excessive intake of anti-inflammatory drugs. Adverse effects were not addressed in the other studies included in this meta-analysis. As said before, these studies included only healthy subjects and required a very short-term use of NSAIDs; they were therefore not designed to address the question of adverse effects. Although acute kidney injury is a common finding in endurance runners, encountered in 34-85\% of ultra-marathoners, and NSAIDs are thought to contribute to acute kidney injury, $35-75 \%$ of ultra-marathoners ingest them during competition [45]. In addition, a double-blind randomized placebo-controlled trial performed under marathon conditions showed increased rates of acute kidney injury in those who took ibuprofen, and although not statistically inferior to placebo by a small margin, there was a number needed to harm of 5.5 people to cause 1 case of acute kidney injury [45]. A similar design could be used 
to evaluate the ability of NSAIDs to enhance sport performance. The study should be a randomized, doubleblind, placebo-controlled clinical trial with time until exhaustion during a running exercise or the performance during a time-trial, a semi-marathon, or a marathon as a primary outcome.

This meta-analysis has some limitations. The search was performed in a limited number of databases; however, it has been shown that using data sources beyond PubMed has a modest impact on the results of systematic reviews of therapeutic interventions [46]. The methodological quality of studies included is poor, the risk of bias is high, and a publication bias cannot be excluded. The funnel plots is symmetric, but the number of studies for each outcome is low, and most of these studies were not registered before being conducted as recommended for comparative studies [47]. Thus, the findings of this work indicate that there is a lack of studies in this area.

\section{Conclusion}

Our meta-analysis does not allow concluding unambiguously on the existence or not of an ergogenic effect of NSAIDs on sport performance. The risks for athletes are not well documented, and there is still a lack of studies adequately designed in this area. The absence of evidence is not evidence of the absence of an effect; since this meta-analysis did not show any effect on pain, this suggests that the trials were not optimally designed. We recommend the conduct of new trials, adequately powered, methodologically sound, using adequate dosage in a real-life setting to address the question of whether NSAIDs have an influence on athletic performance, and provide data for adequate classification by WADA.

\section{Supplementary information}

Supplementary information accompanies this paper at https://doi.org/10. 1186/s40798-020-00247-w.

Additional file 1: Supplementary Figure 1. Forest plot for the primary outcome, maximum performance in the subgroup of trials assessing lbuprofen

Additional file 2: Supplementary Figure 2. Funnel plot for the primary outcome, maximum performance

\section{Abbreviations}

Cl: Confidence interval; FIFA: Fédération Internationale de Football Association; MeSH: Medical Subject Headings; NSAIDs: Non-steroidal antiinflammatory drugs; SE: Standard error; SMD: Standardized mean differences; WADA: World Anti-Doping Agency

\section{Acknowledgements}

The authors thank Mr. Philip Robinson for the assistance in editing the manuscript. The authors also thank Mrs. Whitney Duff and Phil Chilbeck for providing the data.

\section{Transparency}

The corresponding author affirms that this manuscript is an honest, accurate, and transparent account of the meta-analysis being reported; that no important aspects of the meta-analysis have been omitted; and that any discrepancies from the meta-analysis as planned (and, if relevant, registered) have been explained.

\section{Authors' Contributions}

CG, AR, JM, and SO carried out the meta-analysis and wrote the manuscript. NR did the English editing of the manuscript. BK, PN, and CC supervised the meta-analysis. PS provided expertise in sport medicine and protocols. All authors made substantial contributions to the interpretation of data, revised the manuscript, and approved the final version. The corresponding author attests that all listed authors meet authorship criteria and that no others meeting the criteria have been omitted. CC is the guarantor.

\section{Funding}

No funding was allocated.

\section{Availability of Data and Materials}

No additional data available. Only published data were used.

\section{Ethics Approval and Consent to Participate}

No ethical approval was required, since we used only published data.

\section{Consent for Publication}

All authors made revisions to the manuscript and have read and approved the final version.

\section{Competing Interests}

Catherine Cornu, Clémence Grange, Amanda Regalin, Justine Munier, Sonia Ounissi, Natane Reynaud, Behrouz Kassai-Koupai, Pierre Sallet, and Patrice Nony have completed the ICMJE Uniform Disclosure Form and declare no support from any organization for the submitted work, no financial relationships with any organizations that might have an interest in the submitted work in the previous 3 years, and no other relationships or activities that could appear to have influenced the submitted work.

\section{Author details}

${ }^{1}$ INSERM, CIC1407, 69500 Bron, France. ${ }^{2}$ UMR 5558, Université Claude Bernard Lyon 1, 69100 Lyon, France. ${ }^{3}$ Service de Pharmaco-Toxicologie, Hospices Civils de Lyon, 69000 Lyon, France. ${ }^{4}$ Centre d'Investigation Clinique - Hôpital Louis Pradel, 28, Avenue du Doyen Lépine, 69500 Bron, France. ${ }^{5}$ Université Claude Bernard Lyon 1, 69100 Lyon, France. ${ }^{6}$ ASSOCIATION AFT (Athletes For Transparency), 69100 Lyon, France.

Received: 8 September 2019 Accepted: 26 March 2020

Published online: 28 April 2020

References

1. Bacchi S, Palumbo P, Sponta A, Coppolino MF. Clinical pharmacology of non-steroidal anti-inflammatory drugs: a review. Antiinflamm Antiallergy Agents Med Che. 2012;11(1):52-64.

2. Paoloni JA, Milne C, Orchard J, Hamilton B. Non-steroidal anti-inflammatory drugs in sports medicine: guidelines for practical but sensible use. $\mathrm{Br}$ Sports Med. 2009;43(11):863-5.

3. Ziltener JL, Leal S, Fournier PE. Non-steroidal anti-inflammatory drugs for athletes: an update. Ann Phys Rehabil Med. 2010;53(4):278-82 82-8.

4. Corrigan B, Kazlauskas R. Drug testing at the Sydney Olympics. Med J Aust. 2000;173(6):312-3.

5. Lippi G, Franchini M, Guidi GC, Kean WF. Non-steroidal anti-inflammatory drugs in athletes. Br J Sports Med. 2006;40(8):661-2 discussion 2-3.

6. Tscholl PM, Vaso M, Weber A, Dvorak J. High prevalence of medication use in professional football tournaments including the World Cups between 2002 and 2014: a narrative review with a focus on NSAIDs. Br J Sports Med. 2015;49(9):580-2.

7. Gorski T, Cadore EL, Pinto SS, da Silva EM, Correa CS, Beltrami FG, et al. Use of NSAIDs in triathletes: prevalence, level of awareness and reasons for use. Br J Sports Med. 2011;45(2):85-90.

8. Warden SJ. Prophylactic misuse and recommended use of non-steroida anti-inflammatory drugs by athletes. Br J Sports Med. 2009;43(8):548-9.

9. Ekman EF, Ruoff G, Kuehl K, Ralph L, Hormbrey P, Fiechtner J, et al. The COX-2 specific inhibitor Valdecoxib versus tramadol in acute ankle sprain: a 
multicenter randomized, controlled trial. Am j sports med. 2006;34(6):94555.

10. Clarkson PM. Exertional rhabdomyolysis and acute renal failure in marathon runners. Sports med. 2007;37(4-5):361-3.

11. Seedat YK, Aboo N, Naicker S, Parsoo I. Acute renal failure in the "Comrades Marathon" runners. Renal failure. 1989;11(4):209-12.

12. Ungprasert P, Cheungpasitporn W, Crowson CS, Matteson EL. Individual non-steroidal anti-inflammatory drugs and risk of acute kidney injury: a systematic review and meta-analysis of observational studies. Eur J Intern Med. 2015;26(4):285-91.

13. Van Wijck K, Lenaerts K, Van Bijnen AA, Boonen B, Van Loon LJ, Dejong CH, et al. Aggravation of exercise-induced intestinal injury by lbuprofen in athletes. Med Sci Sports Exerc. 2012;44(12):2257-62.

14. Whatmough $S$, Mears $S$, Kipps $C$. Serum sodium changes in marathon participants who use NSAIDs. BMJ open sport exerc med. 2018;4(1):e000364.

15. Agency WA-D. Prohibited List Q\&A. Prohibited List of Substances and Methods. World Anti-Doping Agency; 2014. https://www.wada-ama.org/en/ questions-answers/prohibited-list-qa\#item-1402. Accessed Mar 2020.

16. agency Wad. Prohibited list january 2020. World anti doping agency; 2020 . https://www.wada-ama.org/sites/default/files/wada_2020_english_ prohibited_list_0.pdf. Accessed Mar 2020.

17. Lisse JR, MacDonald K, Thurmond-Anderle ME, Fuchs JE Jr. A double-blind, placebo-controlled study of acetylsalicylic acid (ASA) in trained runners. J Sports Med Phys Fitnes. 1991;31(4):561-4.

18. Roi GS, Garagiola U, Verza P, Spadari G, Radice D, Zecca L, et al. Aspirin does not affect exercise performance. Int J Sports Med. 1994;15(5):224-7.

19. Holgado D, Hopker J, Sanabria D, Zabala M. Analgesics and Sport Performance: Beyond the Pain-Modulating Effects. PM R. 2018;10(1):72-82.

20. Robinson KA, Goodman SN. A systematic examination of the citation of prior research in reports of randomized, controlled trials. Ann intern med. 2011;154(1):50-5.

21. Swingler GH, Volmink J, loannidis JP. Number of published systematic reviews and global burden of disease: database analysis. Bmj. 2003; 327(7423):1083-4.

22. Elbourne DR, Altman DG, Higgins JP, Curtin F, Worthington HV, Vail A. Metaanalyses involving cross-over trials: methodological issues. Int J Epidemiol. 2002;31(1):140-9.

23. Baldwin AC, Stevenson SW, Dudley GA. Nonsteroidal anti-inflammatory therapy after eccentric exercise in healthy older individuals. J Gerontol A Biol Sci Med Sci. 2001;56(8):M510-3.

24. Braun WA, Flynn MG, Jacks DE, McLoughlin T, Sowash J, Lambert CP, et al. Indomethacin does not influence natural cell-mediated cytotoxic response to endurance exercise. J Appl Physiol. 1999;87(6):2237-43.

25. Correa CSCE, Baroni BM, da Silva ER, Bijoldo JM, Pinto RS, Kruel LF. Effects of prophylactic anti-inflammatory non-steroidal ibuprofen on performance in a session of strength training. Rev Bras Med Esporte. 2013;19(2):4.

26. Da Silva E, Pinto RS, Cadore EL, Kruel LF. Nonsteroidal anti-inflammatory drug use and endurance during running in male long-distance runners. J athl train. 2015;50(3):295-302.

27. de Souza CO, Kurauti MA, de Fatima SF, de Morais H, Borba-Murad GR, de Andrade $F G$, et al. Effects of celecoxib and ibuprofen on metabolic disorders induced by Walker-256 tumor in rats. Mol Cell Biochem. 2015; 399(1-2):237-46.

28. Donnelly AE, Maughan RJ, Whiting PH. Effects of ibuprofen on exerciseinduced muscle soreness and indices of muscle damage. Br J Sports Med. 1990;24(3):191-5.

29. Duff WR, Kontulainen SA, Candow DG, Gordon JJ, Mason RS, Taylor-Gjevre $R$, et al. Effects of low-dose ibuprofen supplementation and resistance training on bone and muscle in postmenopausal women: A randomized controlled trial. Bone reports. 2016;5:96-103.

30. Hasson SM, Daniels JC, Divine JG, Niebuhr BR, Richmond S, Stein PG, et al. Effect of ibuprofen use on muscle soreness, damage, and performance: a preliminary investigation. Med sci sports exerc. 1993;25(1):9-17.

31. Hudson GM, Green JM, Bishop PA, Richardson MT. Effects of caffeine and aspirin on light resistance training performance, perceived exertion, and pain perception. Journal of strength and conditioning research. 2008;22(6): 1950-7

32. Krentz JR, Quest B, Farthing JP, Quest DW, Chilibeck PD. The effects of ibuprofen on muscle hypertrophy, strength, and soreness during resistance training. Applied physiology, nutrition, and metabolism = Physiologie appliquee, nutrition et metabolisme. 2008;33(3):470-5.
33. Lecomte JM, Lacroix VJ, Montgomery DL. A randomized controlled trial of the effect of naproxen on delayed onset muscle soreness and muscle strength. Clin J Sport Med. 1998;8(2):82-7.

34. Lilja M, Mandic M, Apro W, Melin M, Olsson K, Rosenborg S, et al. High doses of anti-inflammatory drugs compromise muscle strength and hypertrophic adaptations to resistance training in young adults. Acta physiol. 2018;222(2):1-16.

35. Meamarbashi A, Rajabi A. Preventive effects of 10-day supplementation with saffron and indomethacin on the delayed-onset muscle soreness. Clin J Sport Med. 2015;25(2):105-12.

36. Morgan PT, Vanhatalo A, Bowtell JL, Jones AM, Bailey SJ. Acute ibuprofen ingestion does not attenuate fatigue during maximal intermittent knee extensor or all-out cycling exercise. Appl Physiol Nutr Metab. 2019;44(2):208-15.

37. Olsen NV, Jensen NG, Hansen JM, Christensen NJ, Fogh-Andersen N, Kanstrup IL. Non-steroidal anti-inflammatory drugs and renal response to exercise: a comparison of indomethacin and nabumetone. Clin sci. 1999; 97(4):457-65.

38. Przybylowski J, Obodynski K, Lewicki C, Kuzniar J, Zaborniak S, Drozd S, et al. The influence of aspirin on exercise-induced changes in adrenocorticotrophic hormone (ACTH), cortisol and aldosterone (ALD) concentrations. Eur J Appl Physiol. 2003;89(2):177-83.

39. Rahnama N, Rahmani-Nia F, Ebrahim K. The isolated and combined effects of selected physical activity and ibuprofen on delayed-onset muscle soreness. J sports sci. 2005;23(8):843-50.

40. Semark A, Noakes TD, St Clair Gibson A, Lambert MI. The effect of a prophylactic dose of flurbiprofen on muscle soreness and sprinting performance in trained subjects. J sports sci. 1999;17(3):197-203.

41. Tokmakidis SP, Kokkinidis EA, Smilios I, Douda H. The effects of ibuprofen on delayed muscle soreness and muscular performance after eccentric exercise. J Strength Cond Res. 2003;17(1):53-9.

42. VanHeest JLSJ, Scheett TP, Collins V, Roti M, Anderson J. Effects of Ibuprofen and Vicoprofen ${ }^{\oplus}$ on physical performance after exercise-induced muscle damage. J Sport Rehabil. 2002;11(3):10.

43. Trappe TA, Carroll CC, Dickinson JM, LeMoine JK, Haus JM, Sullivan BE, et al. Influence of acetaminophen and ibuprofen on skeletal muscle adaptations to resistance exercise in older adults. Am J Physiol Regul Integr Comp Physiol. 2011;300(3):R655-62.

44. Higgins JPT TJ, Chandler J, Cumpston M, Li T, Page MJ, Welch VA. Cochrane Handbook for Systematic Reviews of Interventions Version 5.1.0 [updated March 2011] http://handbook.cochrane.org: Cochrane Handbook editorial team; 2011 [updated updated July 2019.

45. Lipman GS, Shea K, Christensen M, Phillips C, Burns P, Higbee R, et al. Ibuprofen versus placebo effect on acute kidney injury in ultramarathons: a randomised controlled trial. EMJ. 2017:34(10):637-42.

46. Halladay CW, Trikalinos TA, Schmid IT, Schmid CH, Dahabreh IJ. Using data sources beyond PubMed has a modest impact on the results of systematic reviews of therapeutic interventions. J Clin Epidemiol. 2015;68(9):1076-84.

47. Zarin DA, Tse T, Williams RJ, Carr S. Trial Reporting in ClinicalTrials.gov - The Final Rule. N Engl J Med. 2016;375(20):1998-2004.

\section{Publisher's Note}

Springer Nature remains neutral with regard to jurisdictional claims in published maps and institutional affiliations.

\section{Submit your manuscript to a SpringerOpen ${ }^{\circ}$ journal and benefit from:}

- Convenient online submission

- Rigorous peer review

- Open access: articles freely available online

- High visibility within the field

- Retaining the copyright to your article

Submit your next manuscript at $>$ springeropen.com 